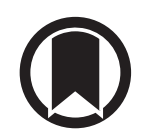

CrossMark

\title{
Assessment of chronic bronchitis and risk factors in young adults: results from BAMSE
}

\author{
Gang Wang ${ }^{1,2,3}$, Jenny Hallberg ${ }^{3,4}$, Petra Um Bergström (10) ${ }^{3,4}$, Christer Janson (10 ${ }^{5}$, \\ Göran Pershagen ${ }^{2,6}$, Olena Gruzieva ${ }^{2,6}$, Marianne van Hage ${ }^{7}$, \\ Antonios Georgelis ${ }^{2,6}$, Anna Bergström ${ }^{2,6}$, Inger Kull2,3,4, Anders Lindén ${ }^{2,8}$ and \\ Erik Melén (102,3,4
}

\begin{abstract}
Affiliations: 'Dept of Integrated Traditional Chinese and Western Medicine, West China Hospital, Sichuan University, Sichuan, China. ${ }^{2}$ Institute of Environmental Medicine, Karolinska Institutet, Stockholm, Sweden. ${ }^{3}$ Dept of Clinical Science and Education, Södersjukhuset, Karolinska Institutet, Stockholm, Sweden. 'Sachs' Children and Youth Hospital, Södersjukhuset, Stockholm, Sweden. ${ }^{5}$ Dept of Medical Sciences: Respiratory, Allergy and Sleep Research, Uppsala University, Uppsala, Sweden. ${ }^{6}$ Centre for Occupational and Environmental Medicine, Region Stockholm, Stockholm, Sweden. ${ }^{7}$ Division of Immunology and Allergy, Dept of Medicine, Karolinska Institutet and Karolinska University Hospital, Stockholm, Sweden. ${ }^{8}$ Dept of Respiratory Medicine and Allergy, Karolinska University Hospital Solna, Stockholm, Sweden.
\end{abstract}

Correspondence: Erik Melén, Dept of Clinical Science and Education Södersjukhuset, Karolinska Institutet, 118 83, Stockholm, Sweden. E-mail: erik.melenaki.se

@ERSpublications

Chronic bronchitis in young adults is strongly associated with recurrent respiratory infections. Besides smoking, our results support the role of early-life environmental exposures for respiratory health in this age group. https://bit.ly/2RNsv $5 z$

Cite this article as: Wang G, Hallberg J, Um Bergström P, et al. Assessment of chronic bronchitis and risk factors in young adults: results from BAMSE. Eur Respir J 2021; 57: 2002120 [https://doi.org/10.1183/ 13993003.02120-2020].

\begin{abstract}
Background: Chronic bronchitis is associated with substantial morbidity among elderly adults, but little is known about its prevalence and risk factors in young adults. Our aim was to assess the prevalence and early-life risk factors for chronic bronchitis in young adults.

Methods: Questionnaire data and clinical measures from the 24-year follow-up of the Swedish BAMSE (Child (Barn), Allergy, Milieu, Stockholm, Epidemiological) cohort were used. We assessed chronic bronchitis $(\mathrm{CB})$ as the combination of cough and mucus production in the morning during winter. Environmental and clinical data from birth and onwards were used for analyses of risk factors.

Results: At the 24-year follow-up, 75\% (n=3064) participants completed the questionnaire and 2030 performed spirometry. The overall prevalence of CB was 5.5\% $(n=158)$ with similar estimates in males and females. $49 \%$ of $\mathrm{CB}$ cases experienced more than three self-reported respiratory infections in the past year compared to $18 \%$ in non-CB subjects $(\mathrm{p}<0.001)$, and $37 \%$ of cases were current smokers (versus $19 \%$ of non-CB cases). Statistically significant lower post-bronchodilator forced expiratory volume in $1 \mathrm{~s} /$ forced vital capacity were observed in $\mathrm{CB}$ compared to non-CB subjects (mean $\mathrm{z}$-score -0.06 versus $0.13, \mathrm{p}=0.027$ ). Daily smoking (adjusted (a)OR 3.85 , $\mathrm{p}<0.001$ ), air pollution exposure (black carbon at ages $1-4$ years aOR 1.71 per $1 \mu \mathrm{g} \cdot \mathrm{m}^{-3}$ increase, $\mathrm{p}=0.009$ ) and exclusive breastfeeding for $\geqslant 4$ months ( $a O R$ 0.66, $\mathrm{p}=0.044$ ) were associated with CB.

Conclusion: Chronic bronchitis in young adults is associated with recurrent respiratory infections. Besides smoking, our results support the role of early-life exposures, such as air pollution and exclusive breastfeeding, for respiratory health later in life.
\end{abstract}




\section{Introduction}

Chronic bronchitis is characterised by cough and hypersecretion of mucus and associated with chronic inflammation in the airways [1]. In addition, chronic bronchitis is associated with acute respiratory health events, including exacerbations [2,3] and hospitalisations [4] as well as airflow obstruction [5], progressive lung function decline [6], and eventually higher all-cause mortality [5].

Chronic bronchitis is common in the general adult population and the prevalence ranges from $3.6 \%$ to $22 \%$ worldwide [7], and from $5.5 \%$ to $7.2 \%$ in Sweden $[8,9]$. Moreover, the prevalence is even higher in smokers with COPD, ranging from $19 \%$ to $74 \%$ [10-12]. Due to the enhanced prevalence in the elderly and patients with COPD $[9,13]$, few studies on chronic bronchitis have focused on young adults. Most of these studies include subjects aged 18-40 years, and report prevalence ranging from $1 \%$ to $10 \%$ [9, 13-15]. However, little is known about the prevalence and early-life risk factors for chronic bronchitis in the specific age group of young adults in their early twenties.

Ongoing exposure to cigarette smoke is known as a primary risk factor for chronic bronchitis, but other risk factors, such as ambient air pollutants, may also play a role [14]. Although the relationship between air pollution exposure in adulthood and chronic bronchitis has been well studied $[13,16]$, no studies have evaluated associations between early-life exposure and later disease. Our previous studies found impaired development of lung function, as well as asthma during childhood and adolescence, to be linked to traffic-related air pollution exposure in infancy [17-19]. Given these facts, we hypothesised that childhood air-pollution exposure and other environmental exposures may influence the risk of chronic bronchitis in young adults. Thus, the aim of this study was to assess the prevalence of chronic bronchitis in young adults in a Swedish population-based birth cohort and to identify early-life risk factors, including environmental exposures, for disease development.

\section{Methods}

\section{Subjects}

In this project, data from the follow-up of the Swedish population-based birth cohort BAMSE (Swedish abbreviation for Child (Barn), Allergy, Milieu, Stockholm, Epidemiological) were used [20-22]. Between February 1994 and November 1996, 4089 infants from inner-city, urban and suburban districts of Stockholm were included in the cohort. Data on background characteristics, respiratory health and exposure factors were obtained from parental questionnaires administered at age of 2 months. Follow-up questionnaires were repeatedly answered by parents at age of $1,2,4,8,12$ and 16 years. The response rates were $96 \%, 94 \%, 91 \%, 84 \%, 82 \%$ and $78 \%$, respectively. At the 24 -year follow-up, questionnaires focusing on respiratory symptoms and key exposures such as smoking habits were answered by the participants themselves. Details about the definitions of health outcomes and covariates are provided in the supplementary material.

The study was approved by the ethics committee of Karolinska Institutet (Stockholm, Sweden; ref 2016/ 1380-31/2), and all participants gave their oral and written informed consent, in accordance with the Declaration of Helsinki.

\section{Measurements and definitions of outcomes}

We assessed chronic bronchitis as the combination of the symptoms of cough and mucus production in the morning during winter (defined as "CB"), which required positive answers to the following two binary-choice questions: 1) "In the winter, do you usually cough as soon as you wake up in the morning?" and 2) "In the winter, do you usually bring up mucus as soon as you wake up in the morning?" [23].

Childhood asthma at ages 1-16 years was defined if at least two of the following three criteria were fulfilled: doctor's diagnosis of asthma ever; wheezing in the past 12 months; and/or use of asthma medication during the past 12 months [24].

Current asthma was defined as a positive answer to doctor diagnosis of asthma, and at least one of the following: wheezing in the past 12 months; or use of asthma medication during the past 12 months.

Lung function was tested according to American Thoracic Society (ATS)/European Respiratory Society (ERS) spirometry criteria [25] using the Jaeger MasterScreen-IOS system (Carefusion Technologies, San Diego, CA, USA) and post-bronchodilator lung function was tested $15 \mathrm{~min}$ after the administration of $400 \mu \mathrm{g}$ salbutamol. The highest values of pre- and post-forced expiratory volume in $1 \mathrm{~s}\left(\mathrm{FEV}_{1}\right)$ and forced

This article has an editorial commentary: https://doi.org/10.1183/13993003.03997-2020

This article has supplementary material available from erj.ersjournals.com 
vital capacity (FVC) were recorded $[19,20]$. Predicted values and z-scores of $\mathrm{FEV}_{1}, \mathrm{FVC}$ and $\mathrm{FEV}_{1} / \mathrm{FVC}$ ratios were calculated for each patient using equations from the Global Lung Function Initiative (GLI) [26] according to age, sex, height and ethnicity. The lower limit of normal (LLN) was defined as the bottom fifth percentile of the predicted value and calculated by GLI equations for every participant.

Fractional exhaled nitric oxide $\left(F_{\text {eNO }}\right)$ was measured using a chemiluminescence analyser (EcoMedics Exhalyzer, Duernten, Switzerland) according to the ATS/ERS guidelines [27].

\section{Definition of air pollution exposure}

Details of air pollution exposure concentrations have been described previously [28]. Briefly, historical emission databases and Gaussian air-dispersion models were used to calculate the time-weighted average outdoor concentration of two representative traffic-related air pollutants (nitrogen oxides $\left(\mathrm{NO}_{\mathrm{x}}\right)$ and black carbon) for different time windows, namely during the first year of life (i.e. $0-1$ years), as well as average exposures since the date of the previous follow-up (i.e. 1-4, 4-8, 8-12 and 12-16 years), according to geocoded lifetime residential, day-care and school addresses. All air pollution concentrations were estimated and presented as continuous variables $\left(\mu \mathrm{g} \cdot \mathrm{m}^{-3}\right)$.

\section{Statistical analysis}

The prevalence of CB in BAMSE was expressed as the percentage of the total number of participants who completed the 24-year questionnaire. Comparisons between participants with and without $\mathrm{CB}$ were performed using ANOVA, Kruskal-Wallis rank, Chi-squared tests and Fisher's exact test, as appropriate. Odds ratios and $95 \%$ confidence intervals of potential risk factors in relation to CB were estimated based on multivariable logistic regression. As concurrent asthma may be associated with cough and mucus production, we performed a sensitivity analysis where participants with current asthma were excluded. p-values $<0.05$ were considered statistically significant. Analyses were performed using the $\mathrm{R}$ software (version 4.0.2; www.r-project.org).

\section{Results}

\section{Baseline characteristics}

Among the 4089 children in the original BAMSE cohort, 3064 (75\%) participants completed the questionnaire at the 24 -year follow-up. Of these respondents, 2890 provided valid information on morning cough and mucus production, and 2030 performed lung function measurements. The overall prevalence of cough only was $3.3 \%$ (95\% CI $2.6-3.9 \%, \mathrm{n}=95)$, mucus production only $9.6 \%$ (95\% CI $8.5-10.6 \%, \mathrm{n}=276$ ), and both cough and mucus production, thus CB, 5.5\% (95\% CI 4.6-6.3\%, $\mathrm{n}=158$ ). There was no difference of CB prevalence between males $(5.5 \%, \mathrm{n}=73)$ and females $(5.5 \%, \mathrm{n}=85)$. Table 1 shows that, compared with non-CB subjects (without cough and mucus production), CB cases had higher body mass index (BMI), smoked more often (former and current smoking and electronic cigarette smoking) and smoked

\begin{tabular}{|c|c|c|c|}
\hline & CB & No CB & p-value \\
\hline Subjects & 158 & 2361 & \\
\hline Age years & $22.4 \pm 0.5$ & $22.4 \pm 0.5$ & 0.361 \\
\hline Female & 85 (53.8) & $1278(54.1)$ & 0.935 \\
\hline BMI $\mathrm{kg} \cdot \mathrm{m}^{-2}$ & $24.03 \pm 4.4$ & $23.15 \pm 3.8$ & 0.005 \\
\hline Education & & & 0.544 \\
\hline Secondary school & $106(67.1)$ & $1503(63.8)$ & \\
\hline High school & 34 (21.5) & $514(21.8)$ & \\
\hline University & $18(11.4)$ & $340(14.4)$ & \\
\hline Smoking status & & & $<0.001$ \\
\hline Never-smoker & $72(45.6)$ & $1628(69.1)$ & \\
\hline Former smoker & $27(17.1)$ & 289 (12.3) & \\
\hline Current smoker, sometimes & $27(17.1)$ & $297(12.6)$ & \\
\hline Current smoker, every day & $32(20.3)$ & $142(6.0)$ & \\
\hline Cigarette consumption per day ${ }^{\#}$ & $4.3(1.1-10.0)$ & $1.4(0.4-5.0)$ & $<0.001$ \\
\hline Electronic cigarette smoking & $11(7.0)$ & $82(3.5)$ & 0.025 \\
\hline
\end{tabular}

Data are presented as $\mathrm{n}$, mean $\pm \mathrm{SD}, \mathrm{n}(\%)$ or median (interquartile range), unless otherwise stated. BMI: body mass index. ${ }^{\#}$ : based on current smokers. 
more cigarettes (cigarette consumption per day). No statistically significant differences were found in relation to age, sex or education.

\section{Respiratory health events and lung function}

Self-reported respiratory symptoms and lung function data for each group are presented in table 2 . In the group of $\mathrm{CB}$ cases, $62 \%$ reported any respiratory symptoms in the past 12 months compared to $19 \%$ in the non-CB group, and the proportion of subjects with emergency department visits due to respiratory symptoms was six times higher among those with CB. Self-reported pneumonia in the past 12 months was more common in the group of $\mathrm{CB}$ cases $(8.3 \%$ versus $2.1 \%)$ as well as self-reported recurrent (more than three) respiratory infections ( $49 \%$ versus $18 \%$ ) compared to the non-CB group. $32 \%$ of the CB cases had concurrent current asthma at 24 years, compared to $8.6 \%$ in subjects without CB. Besides, more subjects in the group of $\mathrm{CB}$ cases were using inhaled steroids (18.5\% versus $4.7 \%$ ) and sensitised to common food allergens at 24 years compared to the non-CB group (16.5\% versus $7.6 \%)$. However, no statistically significant differences were observed for sensitisation to airborne allergens. Compared to subjects without $\mathrm{CB}$, pre- and post-FEV $1 / \mathrm{FVC}$ ratios were lower in the group of $\mathrm{CB}$ cases (mean pre- and post- $\mathrm{z}$-score -0.59 and -0.06 , respectively, versus -0.33 and 0.13 in the non-CB group; $p=0.003$ and $p=0.027$, respectively), and greater change in $\mathrm{FEV}_{1}$ after reversibility test was found (4.0\% $\mathrm{FEV}_{1}$ change compared to baseline value versus $3.0 \%$ in the $\mathrm{CB}$ versus non- $\mathrm{CB}$ group, $\mathrm{p}=0.005$ ). No pronounced differences were

TABLE 2 Respiratory health events and lung function in participants with and without chronic bronchitis (CB)

\begin{tabular}{|c|c|c|c|}
\hline & CB & No CB & p-value \\
\hline Subjects & 158 & 2361 & \\
\hline Self-reported respiratory symptoms ${ }^{\#}$ & $98(62.0)$ & $451(19.1)$ & $<0.001$ \\
\hline Emergency department visits & $14(8.9)$ & $33(1.4)$ & $<0.001$ \\
\hline Self-reported respiratory infections & & & $<0.001$ \\
\hline Never & 6 (3.8) & $339(14.4)$ & \\
\hline $1-3$ & 75 (47.5) & $1591(67.4)$ & \\
\hline$>3$ & $77(48.7)$ & $431(18.3)$ & \\
\hline Self-reported pneumonia & 13 (8.3) & $50(2.1)$ & $<0.001$ \\
\hline Current asthma & $50(31.6)$ & $203(8.6)$ & $<0.001$ \\
\hline Sensitisation to airborne allergens ${ }^{\pi}$ & $60(49.6)$ & $746(41.6)$ & 0.083 \\
\hline Sensitisation to food allergens ${ }^{+}$ & $20(16.5)$ & $137(7.6)$ & $<0.001$ \\
\hline$F_{\mathrm{eNO}} \mathrm{ppb}$ & $11(9-19)$ & $12(8-19)$ & 0.987 \\
\hline Pre-bronchodilator FEV F $_{1} \%$ predicted $^{\S}$ & $95.7 \pm 10.1$ & $97.1 \pm 10.1$ & 0.184 \\
\hline Pre-bronchodilator FEV $<_{1}<L N^{\S}$ & $8(7.7)$ & $74(4.5)$ & 0.140 \\
\hline Pre-bronchodilator FEV 1 z-score ${ }^{\S}$ & $-0.37 \pm 0.9$ & $-0.25 \pm 0.9$ & 0.178 \\
\hline Pre-bronchodilator FVC $\%$ predicted $^{\S}$ & $100.0 \pm 9.7$ & $99.4 \pm 10.3$ & 0.561 \\
\hline Pre-bronchodilator FVC z-score ${ }^{\S}$ & $-0.01 \pm 0.8$ & $-0.06 \pm 0.9$ & 0.557 \\
\hline Pre-bronchodilator FEV 1 /FVC \% & $81.8 \pm 6.3$ & $83.5 \pm 6.1$ & 0.005 \\
\hline Pre-bronchodilator $\mathrm{FEV}_{1} / \mathrm{FVC}_{\mathrm{z}}$-score ${ }^{\S}$ & $-0.59 \pm 0.9$ & $-0.33 \pm 0.9$ & 0.003 \\
\hline \multicolumn{4}{|l|}{ Reversibility test } \\
\hline Change in $\mathrm{FEV}_{1} \mathrm{~mL}$ & $139(80-220)$ & $115(54-195)$ & 0.011 \\
\hline Change in $\mathrm{FEV}_{1} \%$ baseline value & $4.0(2.1-5.7)$ & $3.0(1.3-4.9)$ & 0.005 \\
\hline Post-bronchodilator FEV $1 \%$ predicted $^{\S}$ & $99.2 \pm 9.8$ & $100.1 \pm 9.9$ & 0.372 \\
\hline Post-bronchodilator FEV $1<L_{1} \mathrm{LN}^{\S}$ & $4(4.2)$ & 29 (1.9) & $0.117^{f}$ \\
\hline Post-bronchodilator FEV 1 z-score ${ }^{\S}$ & $-0.07 \pm 0.8$ & $0.02 \pm 0.9$ & 0.360 \\
\hline Post-bronchodilator FVC $\%$ predicted $^{\S}$ & $99.3 \pm 9.8$ & $98.9 \pm 10.4$ & 0.723 \\
\hline Post-bronchodilator FVC z-score ${ }^{\S}$ & $-0.07 \pm 0.8$ & $-0.10 \pm 0.9$ & 0.731 \\
\hline Post-bronchodilator $\mathrm{FEV}_{1} / \mathrm{FVC} \%$ & $85.4 \pm 5.6$ & $86.6 \pm 5.3$ & 0.035 \\
\hline Post-bronchodilator FEV ${ }_{1} /$ FVC z-score ${ }^{\S}$ & $-0.06 \pm 0.8$ & $0.13 \pm 0.8$ & 0.027 \\
\hline
\end{tabular}

Data are presented as $\mathrm{n}, \mathrm{n}(\%)$, median (interquartile range) or mean $\pm \mathrm{SD}$, unless otherwise stated. $F_{\mathrm{eNO}}$ : fractional exhaled nitric oxide; $F_{E V}$ : forced expiratory volume in $1 \mathrm{~s}$; LLN: lower limit of normal; FVC: forced vital capacity. \#: self-reported respiratory symptoms were assessed as any troublesome breathing, chest tightness or wheezing during the past 12 months; ": sensitisation was assessed to a mix of common airborne allergens with Phadiatop (ImmunoCAP System; ThermoFisher, Uppsala, Sweden), and a positive test was defined as specific immunoglobulin $\left.(\mathrm{lg}) \mathrm{E} \geqslant 0.35 \mathrm{kU}_{\mathrm{A}} \cdot \mathrm{L}^{-1}\right)$; ${ }^{+}$: sensitisation was assessed to a mix of common food allergens with $\mathrm{fx} 5$ (ImmunoCAP System), and a positive test was defined as specific $\operatorname{lgE}$ $\left.\geqslant 0.35 \mathrm{kU}_{\mathrm{A}} \cdot \mathrm{L}^{-1}\right) ;{ }^{\S}$ : based on the reference equation from the Global Lung Initiative 2012 [26]; $f^{\text {: }}$ based on Fisher's exact test. 
detected for pre- and post-FEV 1 , pre- and post-FVC or $F_{\mathrm{eNO}}$ between subjects with or without CB. Sensitivity analyses that excluded current asthma subjects showed overall similar results, with the addition that more cases with CB had pre- and post-FEV 1 below LLN compared to the non-case group (9.9\% and $6.3 \%$, respectively, versus $4.3 \%$ and $1.8 \%$; $=0.027$ and $p=0.011$, respectively; supplementary table E1).

\section{Risk factors for $C B$ in young adults}

In regression models adjusted for age, sex and BMI (table 3), childhood asthma was a strong risk factor related to $\mathrm{CB}$ in young adults (OR 3.08, 95\% CI 2.17-4.35). In mutually adjusted models exploring the role of environmental exposures, we found that smoking status (former smoker adjusted (a)OR 1.90, 95\% CI 1.16-3.14; current smoking (sometimes) aOR 1.99, 95\% CI 1.22-3.26; current smoking (daily) aOR 3.85, 95\% CI 2.32-6.39; figure 1), and exposure to air pollution (black carbon concentration at age 14 years aOR $1.71,95 \%$ CI $1.14-2.57$ per $1 \mu \mathrm{g} \cdot \mathrm{m}^{-3}$ increase; figure 1 ; NOx concentration at age $1-4$ years aOR $1.01,95 \%$ CI $1.00-1.03$ per $1 \mu \mathrm{g} \cdot \mathrm{m}^{-3}$ increase; supplementary figure E1) were independent risk factors for $\mathrm{CB}$. Exclusive breastfeeding for $\geqslant 4$ months was found to be a protective factor (aOR $0.66,95 \%$

TABLE 3 Distribution of potential risk factors for chronic bronchitis (CB) among young adults from the BAMSE (Child (Barn), Allergy, Milieu, Stockholm, Epidemiological) birth cohort

\begin{tabular}{|c|c|c|c|c|}
\hline & \multirow[t]{2}{*}{ CB } & \multirow[t]{2}{*}{ No CB } & \multicolumn{2}{|c|}{ Logistic regression model ${ }^{\#}$} \\
\hline & & & OR $(95 \% \mathrm{CI})$ & p-value \\
\hline Subjects & 158 & 2361 & & \\
\hline Electronic cigarette smoking & $11(7.0)$ & $82(3.5)$ & $1.916(0.937-3.573)$ & 0.055 \\
\hline \multicolumn{5}{|l|}{ Parental occupation } \\
\hline Unemployed/blue collar & $18(12.9)$ & $212(10.1)$ & Ref. & \\
\hline Low white collar & $60(43.2)$ & $843(40.0)$ & $0.874(0.489-1.467)$ & 0.555 \\
\hline High white collar & $61(43.9)$ & 1050 (49.9) & $0.705(0.408-1.219)$ & 0.211 \\
\hline \multicolumn{5}{|l|}{ Parental education } \\
\hline University & $71(44.9)$ & 1365 (57.9) & Ref. & \\
\hline Primary school/high school & $87(55.1)$ & $993(42.1)$ & $1.618(1.167-2.249)$ & 0.004 \\
\hline Parental asthma & $33(21.6)$ & $444(18.9)$ & $1.174(0.776-1.730)$ & 0.432 \\
\hline $\begin{array}{l}\text { Exclusive breastfeeding for } \\
\geqslant 4 \text { months }\end{array}$ & $115(75.7)$ & $1857(80.8)$ & $0.743(0.510-1.107)$ & 0.132 \\
\hline $\begin{array}{l}\text { Maternal smoking during } \\
\text { pregnancy }\end{array}$ & 21 (13.3) & $253(10.7)$ & $1.249(0.752-1.979)$ & 0.365 \\
\hline Parental smoking during childhood & $65(41.4)$ & 644 (27.3) & $1.822(1.301-2.563)$ & $<0.001$ \\
\hline Premature birth & 9 (5.7) & $129(5.5)$ & $1.026(0.475-1.957)$ & 0.942 \\
\hline Low birthweight & $4(2.5)$ & $84(3.6)$ & $0.728(0.220-1.781)$ & 0.541 \\
\hline $\begin{array}{l}\text { Respiratory syncytial virus } \\
\text { infection/pneumonia during } \\
\text { infancy }\end{array}$ & $14(9.2)$ & $164(7.1)$ & $1.282(0.691-2.205)$ & 0.399 \\
\hline Bronchitis during infancy & $12(7.8)$ & $178(7.8)$ & $0.975(0.503-1.728)$ & 0.937 \\
\hline Pneumonia at age $0-4$ years & 16 (10.3) & $249(10.7)$ & $0.950(0.536-1.576)$ & 0.851 \\
\hline Childhood asthma at age $1-4$ years & 31 (19.9) & 228 (9.8) & $2.129(1.367-3.225)$ & 0.001 \\
\hline Childhood asthma at age $1-8$ years & 42 (26.9) & $275(11.7)$ & $2.629(1.773-3.831)$ & $<0.001$ \\
\hline $\begin{array}{l}\text { Childhood asthma at age } \\
1-16 \text { years }\end{array}$ & $59(37.6)$ & $367(15.6)$ & $3.082(2.166-4.351)$ & $<0.001$ \\
\hline \multicolumn{5}{|l|}{ Nitrogen oxides $\mu \mathrm{g} \cdot \mathrm{m}^{-3}$} \\
\hline Age $0-1$ years & $29.12(20.3-45.0)$ & $29.3(18.3-42.5)$ & $1.006(0.997-1.014)$ & 0.195 \\
\hline Age $1-4$ years & $25.8(16.9-37.7)$ & $24.2(15.3-33.6)$ & $1.011(1.000-1.022)$ & 0.038 \\
\hline Age $4-8$ years & $20.5(13.1-29.8)$ & $18.2(12.1-27.1)$ & $1.010(0.994-1.025)$ & 0.192 \\
\hline Age $8-12$ years & $14.2(10.0-22.9)$ & $13.8(10.1-22.2)$ & $1.002(0.983-1.020)$ & 0.837 \\
\hline Age $12-16$ years & $11.7(7.9-17.1)$ & $11.3(8.3-18.1)$ & $0.997(0.970-1.022)$ & 0.811 \\
\hline \multicolumn{5}{|l|}{ Black carbon $\mu \mathrm{g} \cdot \mathrm{m}^{-3}$} \\
\hline Age $0-1$ years & $0.97(0.8-1.4)$ & $0.97(0.7-1.3)$ & $1.278(0.905-1.764)$ & 0.149 \\
\hline Age $1-4$ years & $0.96(0.7-1.3)$ & $0.89(0.7-1.2)$ & $1.575(1.060-2.289)$ & 0.020 \\
\hline Age $4-8$ years & $0.87(0.7-1.2)$ & $0.81(0.6-1.1)$ & 1.388 (0.849-2.205) & 0.177 \\
\hline Age $8-12$ years & $0.71(0.6-1.0)$ & $0.70(0.6-0.9)$ & $1.070(0.585-1.876)$ & 0.820 \\
\hline Age $12-16$ years & $0.66(0.6-0.8)$ & $0.65(0.5-0.8)$ & $0.916(0.350-2.249)$ & 0.853 \\
\hline
\end{tabular}

Data are presented as $\mathrm{n}, \mathrm{n}(\%)$ or median (interquartile range), unless otherwise stated. ${ }^{\text {: }}$ results after adjustment for age, sex and body mass index. 


\begin{tabular}{|c|c|c|c|c|c|}
\hline Variables & OR & $95 \% \mathrm{Cl}$ & $p$-value & & \\
\hline Age years & 0.835 & $0.551-1.264$ & 0.393 & $\longmapsto$ & $\neg$ \\
\hline Male sex & 1.056 & $0.741-1.506$ & 0.762 & 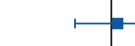 & $\longmapsto$ \\
\hline $\mathrm{BMI} \mathrm{kg} \cdot \mathrm{m}^{-2}$ & 1.038 & $0.996-1.081$ & 0.073 & 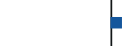 & \\
\hline Former smoker & 1.904 & $1.156-3.138$ & 0.011 & & $\longmapsto$ \\
\hline Current smoker, sometimes & 1.994 & $1.219-3.261$ & 0.006 & & $\longmapsto$ \\
\hline Current smoker, daily & 3.846 & $2.315-6.387$ & $<0.001$ & & $\longmapsto$ \\
\hline Parental education, primary/high school & 1.420 & $0.984-2.049$ & 0.061 & & $\longrightarrow$ \\
\hline Parental smoking during childhood & 1.370 & $0.943-1.990$ & 0.099 & & $\longrightarrow$ \\
\hline $\mathrm{BC}$ concentration at age $1-4$ years, $1 \mu \mathrm{g} \cdot \mathrm{m}^{-3}$ & 1.715 & $1.143-2.572$ & 0.009 & & $\longmapsto$ \\
\hline \multirow[t]{2}{*}{ Exclusive breastfeeding for $\geqslant 4$ months } & 0.658 & $0.438-0.989$ & 0.044 & $\leftrightarrow$ & \\
\hline & & & & 0.5 & 2.0 \\
\hline
\end{tabular}

FIGURE 1 Mutually adjusted logistic regression analyses for chronic bronchitis among young adults from the BAMSE (Child (Barn), Allergy, Milieu, Stockholm, Epidemiological) birth cohort. The model included age, sex, body mass index (BMI), smoking, parental education, parental smoking during childhood, air pollution at age 1-4 years (black carbon (BC)) and exclusive breastfeeding for $\geqslant 4$ months as covariates.

CI 0.44-0.99). Subgroup analyses of smoking history showed that the risk of CB was particularly increased for a combination of parental smoking during childhood and ever-smoking, defined as former or current smoking (aOR 3.63, 95\% CI 2.33-5.64 compared to nonexposed nonsmokers; supplementary table E2), while a smaller risk increase was observed for ever-smokers who were not exposed to parental smoking during childhood (aOR 1.58, 95\% CI 0.98-2.50 with significant OR for interaction 2.79, 95\% CI 1.316.17). There was no clear association between parental smoking and $\mathrm{CB}$ in never-smokers. In addition, electronic smoking (e-smoking) trended to be associated with and increased risk of CB (OR 1.92, 95\% CI 0.99-3.72; table 3), but no clear association were observed between other potential risk factors (i.e. parental occupation, parental asthma, maternal smoking during pregnancy, premature birth, low birthweight, bronchitis during infancy, respiratory syncytial virus infection/pneumonia during early childhood and air pollution during other time windows) and CB.

Sensitivity analyses that excluded subjects with current asthma showed overall similar results with significant associations for smoking status and air pollution exposure, although estimates for exclusive breastfeeding for $\geqslant 4$ months became nonsignificant (aOR 0.77, 95\% CI 0.46-1.27; supplementary figure E2).

\section{Discussion}

In the present study on data from a population-based birth cohort, the overall prevalence of $\mathrm{CB}$ in young adults was 5.5\%, with similar estimates in males and females. The group of cases with $\mathrm{CB}$ had more self-reported respiratory infections and emergency department visits in the past 12 months compared to the group of subjects without CB. Furthermore, using the longitudinal data in our BAMSE birth cohort, we found that previous or current smoking and early-life air pollution exposure were risk factors for $\mathrm{CB}$, while exclusive breastfeeding for $\geqslant 4$ months or more was a protective factor. These findings were robust after adjustment for several potential confounders, and support the role of early-life events in later respiratory health [29].

\section{Smoking as risk factor for chronic bronchitis}

In Sweden, the prevalence of chronic bronchitis in adults aged $<45$ years has decreased from $\sim 12 \%$ in the 1990s [30] to $\sim 4 \%$ after the 2000 s $[9,13,14]$. The decrease in prevalence is believed to be mostly due to decreased smoking in the general population during the same periods [9, 31]. In the 1990 s, $>30 \%$ of young adults in their twenties in Stockholm were current smokers [32], while the prevalence of current smoking (sometimes or daily) was found to be $20.8 \%$ in our BAMSE study. As expected, cigarette smoking strongly increased the risk of CB (almost four-fold increased risk for current daily smoking) in our study. In addition, the risk increase for smoking was found to be particularly high in study participants who were also exposed to parental smoking during childhood (with significant interaction effect); a finding that underlines the combined effects, as suggested earlier [33]. Thus, our results confirm that even a short duration of smoking, and in particular, the combination of smoking and parental smoking exposure, may lead to chronic bronchitis in young adults. As persistent chronic bronchitis symptoms have been found to 
accelerate the decline in $\mathrm{FEV}_{1}$, and chronic bronchitis symptom prevalence following smoking cessation returned to levels seen in never-smokers [34], decreasing cigarette smoke exposure would be an essential way to improve chronic bronchitis-related symptoms as well as long-term health effects.

The use of electronic cigarettes has increased rapidly among young adults in the United States and increases the risk of chronic bronchitis [35]. In our study, e-smoking tended to increase the risk of CB (two-fold), but this association did not reach statistical significance, partly because of the relatively low prevalence of e-smoking in our study, reflecting the situation in Sweden [36].

\section{Early-life environmental risk factors}

To our knowledge, ours is the first study to investigate the association between early-life air pollution exposure and chronic bronchitis in truly young adults. The long-term effects of exposure to air pollution on chronic bronchitis in middle-aged adults and elderly have been investigated previously [16]. In children, it is well known that short-term exposure to air pollution is associated with exacerbations of respiratory infections [37], and long-term exposure is associated with decreased lung function development [18, 19] and wheezing/asthma [38]. In particular, early-life black carbon exposure has been related to wheezing, cough and respiratory infections in preschool and school children [38, 39]. In our current study, we explored the relationship between early-life black carbon and $\mathrm{NO}_{\mathrm{x}}$ exposure and $\mathrm{CB}$ in young adults and found that black carbon and $\mathrm{NO}_{\mathrm{x}}$ concentration at age 1-4 years was an independent risk factor. This relationship was robust to adjustment for several potential confounders, and after the exclusion of participants with current asthma. The levels of black carbon and $\mathrm{NO}_{\mathrm{x}}$ in Stockholm mainly reflect local emissions from road traffic [40], which implies that this intervenable exposure may play an important role in the aetiology of chronic bronchitis in young adults, particularly as air pollution in Stockholm are lower than in most other cities. Another early-life exposure, exclusive breastfeeding, was found to be an independent protective factor for CB. In our previous study, exclusive breastfeeding for $\geqslant 4$ months reduced the risk of asthma up to the age of 8 years [21]. In other studies, exclusive breastfeeding has been associated with reduced risk of childhood respiratory infections [41], which in the long run might help to protect from chronic bronchitis. Childhood asthma per se was associated with CB in our study, and the associations between exclusive breastfeeding and CB were also somewhat attenuated after the exclusion of participants with current asthma (OR decreased from 0.66 to 0.77). Notably, the relationship between breastfeeding, childhood asthma and subsequent $\mathrm{CB}$ will require additional studies for validation. Since current asthma also leads to cough and mucus production, it is difficult to say whether asthma is a mediator or confounder in relation to analyses of environmental factors and $\mathrm{CB}$, even if asthma and CB display different pathologies [42].

\section{Clinical respiratory events and airway obstruction}

Mucus hypersecretion and decreased mucociliary clearance are considered as basic pathologic features of chronic bronchitis $[1,3]$, and accumulated mucus that cannot be expectorated typically triggers respiratory symptoms and intermittent infections [43]. Our study showed that almost half of the cases in the CB group had experienced more than three episodes of respiratory infections per year, which is more than 2.5-fold higher than the group of subjects without CB. Moreover, emergency department visits and history of pneumonia were reported approximately six and four times more frequently, respectively, in the $\mathrm{CB}$ group. The incidence and severity of acute exacerbations in patients with $\mathrm{CB}$ may accelerate the progression of disease severity, including loss of lung function [3]. Chronic bronchitis may exist with or without airway obstruction $[2,11]$. In our study, we found that pre- and post-bronchodilator $\mathrm{FEV}_{1} / \mathrm{FVC}$ $\mathrm{z}$-scores were significantly lower in subjects with CB. Although absolute differences were small, our results suggest early signs of airway obstruction in this group of cases who also presented with higher FEV 1 change from baseline in the reversibility test. Furthermore, a sensitivity analysis excluding current asthma patients confirmed lower $\mathrm{FEV}_{1} / \mathrm{FVC}$ z-scores in the group of cases with $\mathrm{CB}$, and also a larger proportion of subjects with pre- and post-FEV $\mathrm{F}_{1}$ below the LLN compared to the group of subjects without $\mathrm{CB}$. As recently reported by BREYER-KOHANSAL et al. [44], CB relates to not only pre-bronchodilator $\mathrm{FEV}_{1} / \mathrm{FVC}$ ratio $<\mathrm{LLN}$, but also pre-bronchodilator $\mathrm{FEV}_{1}<\mathrm{LLN}$ in adults. These results imply that $\mathrm{CB}$ in this age group is associated with airflow limitation, albeit with limited clinical importance at this stage. However, long-term effects of $\mathrm{CB}$ on the risk of COPD have been reported [5]. No association with $F_{\mathrm{eNO}}$ levels was observed, but interestingly, we found increased sensitisation to food allergens in the group of cases with $\mathrm{CB}$ compared to the group of subjects without $\mathrm{CB}$, and after the exclusion of patients with asthma. To the best of our knowledge, no study has previously explored the relationship between food sensitisation and $\mathrm{CB}$ and it is known that immunoglobulin (Ig)E sensitisation to food allergens may cause respiratory symptoms and/or inflammation through systemic inflammation [45]. Besides, food allergy in children typically leads to food avoidance [46], and possibly to insufficient intake of dietary antioxidants. We have previously shown that low dietary intake of antioxidants in school age is associated with worse lung 
function development among school children with asthma [47]. Thus, it is tempting to speculate that specific food intake may influence the development of $\mathrm{CB}$ through altered intake of antioxidants and related mechanisms. Whether systemic inflammation or such dietary factors relate to food sensitisation leads to CB needs to be explored in more detail.

\section{Strengths and limitations}

Our study has the strength of using data from a large population-based birth cohort with a high response rate, i.e. $75 \%$ from baseline at the 24 -year follow-up. We used several objectively measured datasets for clinical characterisation, e.g. spirometry, reversibility test, IgE data, as well as for risk factor analyses, e.g. air pollution data. Besides, the precision of the air pollution exposure assessment in the children was enhanced by not only considering residential addresses, but also addresses of daycare and schools. The use of the longitudinal data in BAMSE allowed us to explore early-life risk factors for later $\mathrm{CB}$, with relatively little risk of bias and problems with selection, which is crucial for improving the understanding the origin of the disease.

Our study has some limitations. Firstly, our definition of chronic bronchitis is based on questionnaire data on cough and mucus symptoms during winter without any time period specified, which differs from the classic definition that requires two consecutive years [23]. Therefore, we have chosen to describe our outcomes as "assessment of chronic bronchitis" (CB) rather than "chronic bronchitis". In this context, it is important to consider that, in the literature, the definition of chronic bronchitis varies, in particular in epidemiological studies [7]. Secondly, although we explored well-known risk factors for respiratory disease, our analyses should be considered exploratory for this age group, and as such, we didn't correct for multiple tests. However, our findings were robust after adjustment for several potential confounders. Thirdly, we are aware that misclassification of asthma as chronic bronchitis cannot be excluded, but importantly, our sensitivity analysis in participants without current asthma showed congruent results. Besides, the self-report of respiratory health events by participants is a potential limitation of this study, as well as a lack of laboratory workup for the detection of virus or bacteria in conjunction with reported respiratory tract infection. In addition, critically ill new-borns were not included in the BAMSE study, which limits our possibility to assess the influence of extreme prematurity and very low birthweight.

\section{Conclusions}

The overall prevalence of chronic bronchitis in our population-based birth cohort BAMSE is $5.5 \%$ at 24 years of age. Recurrent respiratory infections may be as common in young adult patients with chronic bronchitis as in elderly patients. We identified current and former smoking as well as early-life air pollution exposures and childhood asthma as potential risk factors, and exclusive breastfeeding as a protective factor for chronic bronchitis, which underline the importance of early life events for maintaining lung health during the life-course.

Acknowledgements: The authors thank all BAMSE (Swedish abbreviation for Child, Allergy, Milieu, Stockholm, Epidemiological) cohort participants, nurses and researchers.

Author contributions: J. Hallberg, A. Lindén and E. Melén designed the study and outlined the contents of the manuscript. G. Wang was responsible for the practical conduct of the study, including the planning, coordination and analysis of the data, and the writing the manuscript under the supervision by E. Melén. J. Hallberg had overall responsibility for the fractional exhaled nitric oxide and the lung function measurements at 24 years of age. G. Pershagen and O. Gruzieva had overall responsibility for the air pollution data. P. Um Bergström, C. Janson, M. van Hage, A. Georgelis, A. Bergström and I. Kull revised the work critically for the content. All authors contributed to the interpretation of the data and approved the final manuscript prior to its submission.

Conflict of interest: G. Wang has nothing to disclose. J. Hallberg has nothing to disclose. P. Um Bergström has nothing to disclose. C. Janson has nothing to disclose. G. Pershagen has nothing to disclose. O. Gruzieva has nothing to disclose. M. van Hage reports personal fees for lectures from Thermo Fisher Scientific and ALK, outside the submitted work. A. Georgelis has nothing to disclose. A. Bergström has nothing to disclose. I. Kull has nothing to disclose. A. Lindén has nothing to disclose. E. Melén has nothing to disclose.

Support statement: This study was supported by grants from the Swedish Research Council, the Swedish Research Council for Health, Working Life and Welfare, Formas, the Swedish Heart-Lung Foundation, the European Research Council (TRIBAL, grant agreement 757919), Strategic Research Area (SFO) Epidemiology, Karolinska Institutet and Region Stockholm (ALF project, and for cohort and database maintenance), Swedish Asthma and Allergy Association's Research Foundation, and The Cancer and Allergy Foundation. Thermo Fisher Scientific (Uppsala, Sweden) provided reagents for IgE analyses. G. Wang is sponsored by the China Scholarship Council (CSC, File No. 201906240227). O. Gruzieva is supported by the Swedish Research Council for Health, Working life and Welfare (FORTE 2017-01146). Funding information for this article has been deposited with the Crossref Funder Registry. 


\section{References}

1 Kesimer M, Ford AA, Ceppe A, et al. Airway mucin concentration as a marker of chronic bronchitis. $N$ Engl $J$ Med 2017; 377: 911-922.

2 Martinez $\mathrm{CH}$, Kim V, Chen Y, et al. The clinical impact of non-obstructive chronic bronchitis in current and former smokers. Respir Med 2014; 108: 491-499.

3 Boucher RC. Muco-obstructive lung diseases. N Engl J Med 2019; 380: 1941-1953.

4 Pelkonen MK, Notkola I-LK, Laatikainen TK, et al. Chronic bronchitis in relation to hospitalization and mortality over three decades. Respir Med 2017; 123: 87-93.

5 Guerra S, Sherrill DL, Venker C, et al. Chronic bronchitis before age 50 years predicts incident airflow limitation and mortality risk. Thorax 2009; 64: 894-900.

6 Vestbo J, Prescott E, Lange P. Association of chronic mucus hypersecretion with FEV 1 decline and chronic obstructive pulmonary disease morbidity. Copenhagen City Heart Study Group. Am J Respir Crit Care Med 1996; 153: $1530-1535$.

7 Kim V, Criner GJ. Chronic bronchitis and chronic obstructive pulmonary disease. Am J Respir Crit Care Med 2013; 187: 228-237.

8 Holm M, Kim JL, Lillienberg L, et al. Incidence and prevalence of chronic bronchitis: impact of smoking and welding. The RHINE study. Int J Tuberc Lung Dis 2012; 16: 553-557.

9 Axelsson M, Ekerljung L, Eriksson J, et al. Chronic bronchitis in West Sweden - a matter of smoking and social class. Eur Clin Respir J 2016; 3: 30319.

10 Danielsson P, Ólafsdóttir IS, Benediktsdóttir B, et al. The prevalence of chronic obstructive pulmonary disease in Uppsala, Sweden - the Burden of Obstructive Lung Disease (BOLD) study: cross-sectional population-based study. Clin Respir J 2012; 6: 120-127.

11 Kim V, Han MK, Vance GB, et al. The chronic bronchitic phenotype of COPD: an analysis of the COPDGene Study. Chest 2011; 140: 626-633.

12 Burgel P-R, Nesme-Meyer P, Chanez P, et al. Cough and sputum production are associated with frequent exacerbations and hospitalizations in COPD subjects. Chest 2009; 135: 975-982.

13 Lindgren A, Stroh E, Montnémery P, et al. Traffic-related air pollution associated with prevalence of asthma and COPD/chronic bronchitis. A cross-sectional study in Southern Sweden. Int J Health Geogr 2009; 8: 2.

14 Cerveri I, Accordini S, Verlato G, et al. Variations in the prevalence across countries of chronic bronchitis and smoking habits in young adults. Eur Respir J 2001; 18: 85-92.

15 Harmsen L, Thomsen SF, Ingebrigtsen T, et al. Chronic mucus hypersecretion: prevalence and risk factors in younger individuals. Int J Tuberc Lung Dis 2010; 14: 1052-1058.

16 Cai Y, Schikowski T, Adam M, et al. Cross-sectional associations between air pollution and chronic bronchitis: an ESCAPE meta-analysis across five cohorts. Thorax 2014; 69: 1005-1014.

17 Gehring U, Wijga AH, Hoek G, et al. Exposure to air pollution and development of asthma and rhinoconjunctivitis throughout childhood and adolescence: a population-based birth cohort study. Lancet Respir Med 2015; 3: 933-942.

18 Schultz ES, Gruzieva O, Bellander T, et al. Traffic-related air pollution and lung function in children at 8 years of age: a birth cohort study. Am J Respir Crit Care Med 2012; 186: 1286-1291.

19 Schultz ES, Hallberg J, Bellander T, et al. Early-life exposure to traffic-related air pollution and lung function in adolescence. Am I Respir Crit Care Med 2016; 193: 171-177.

20 Hallberg J, Thunqvist P, Schultz ES, et al. Asthma phenotypes and lung function up to 16 years of age - the BAMSE cohort. Allergy 2015; 70: 667-673.

21 Kull I, Melen E, Alm J, et al. Breast-feeding in relation to asthma, lung function, and sensitization in young schoolchildren. J Allergy Clin Immunol 2010; 125: 1013-1019.

22 Melén E, Bergström A, Kull I, et al. Male sex is strongly associated with IgE-sensitization to airborne but not food allergens: results up to age 24 years from the BAMSE birth cohort. Clin Transl Allergy 2020; 10: 15.

23 Medical Research Council Committee on the Aetiology of Chronic Bronchitis. Definition and classification of chronic bronchitis for clinical and epidemiological purposes. A report to the Medical Research Council by their Committee on the Aetiology of Chronic Bronchitis. Lancet 1965; 1: 775-779.

24 Pinart M, Benet M, Annesi-Maesano I, et al. Comorbidity of eczema, rhinitis, and asthma in IgE-sensitised and non-IgE-sensitised children in MeDALL: a population-based cohort study. Lancet Respir Med 2014; 2: 131-140.

25 Miller MR, Hankinson J, Brusasco V, et al. Standardisation of spirometry. Eur Respir J 2005; 26: 319-338.

26 Quanjer PH, Stanojevic S, Cole TJ, et al. Multi-ethnic reference values for spirometry for the 3-95-yr age range: the global lung function 2012 equations. Eur Respir J 2012; 40: 1324-1343.

27 American Thoracic Society, European Respiratory Society. ATS/ERS recommendations for standardized procedures for the online and offline measurement of exhaled lower respiratory nitric oxide and nasal nitric oxide, 2005. Am J Respir Crit Care Med 2005; 171: 912-930.

28 Segersson D, Eneroth K, Gidhagen L, et al. Health impact of $\mathrm{PM}_{10}, \mathrm{PM}_{2.5}$ and black carbon exposure due to different source sectors in Stockholm, Gothenburg and Umea, Sweden. Int J Environ Res Public Health 2017; 14: 742 .

29 Agusti A, Faner R, Donaldson G, et al. Chronic Airway Diseases Early Stratification (CADSET): a new ERS Clinical Research Collaboration. Eur Respir J 2019; 53: 1900217.

30 Björnsson E, Plaschke P, Norrman E, et al. Symptoms related to asthma and chronic bronchitis in three areas of Sweden. Eur Respir J 1994; 7: 2146-2153.

31 Janson C, Künzli N, de Marco R, et al. Changes in active and passive smoking in the European Community Respiratory Health Survey. Eur Respir J 2006; 27: 517-524.

32 Pallasaho $\mathrm{P}$, Lundbäck B, Meren M, et al. Prevalence and risk factors for asthma and chronic bronchitis in the capitals Helsinki, Stockholm, and Tallinn. Respir Med 2002; 96: 759-769.

33 Guerra S, Stern DA, Zhou M, et al. Combined effects of parental and active smoking on early lung function deficits: a prospective study from birth to age 26 years. Thorax 2013; 68: 1021-1028.

34 Allinson JP, Hardy R, Donaldson GC, et al. The presence of chronic mucus hypersecretion across adult life in relation to chronic obstructive pulmonary disease development. Am J Respir Crit Care Med 2016; 193: 662-672. 
35 McConnell R, Barrington-Trimis JL, Wang K, et al. Electronic cigarette use and respiratory symptoms in adolescents. Am J Respir Crit Care Med 2017; 195: 1043-1049.

36 Hedman L, Backman H, Stridsman C, et al. Association of electronic cigarette use with smoking habits, demographic factors, and respiratory symptoms. JAMA Netw Open 2018; 1: e180789.

37 Nhung NTT, Schindler C, Dien TM, et al. Acute effects of ambient air pollution on lower respiratory infections in Hanoi children: an eight-year time series study. Environ Int 2018; 110: 139-148.

38 Brauer M, Hoek G, Smit HA, et al. Air pollution and development of asthma, allergy and infections in a birth cohort. Eur Respir J 2007; 29: 879-888.

39 Gehring U, Wijga $\mathrm{AH}$, Brauer M, et al. Traffic-related air pollution and the development of asthma and allergies during the first 8 years of life. Am J Respir Crit Care Med 2010; 181: 596-603.

40 Ljungman PLS, Andersson N, Stockfelt L, et al. Long-term exposure to particulate air pollution, black carbon, and their source components in relation to ischemic heart disease and stroke. Environ Health Perspect 2019; 127: 107012.

41 Victora CG, Bahl R, Barros AJD, et al. Breastfeeding in the 21st century: epidemiology, mechanisms, and lifelong effect. Lancet 2016; 387: 475-490.

42 Mauad T, Dolhnikoff M. Pathologic similarities and differences between asthma and chronic obstructive pulmonary disease. Curr Opin Pulm Med 2008; 14: 31-38.

43 Fahy JV, Dickey BF. Airway mucus function and dysfunction. N Engl J Med 2010; 363: 2233-2247.

44 Breyer-Kohansal R, Faner R, Breyer M-K, et al. Factors associated with low lung function in different age bins in the general population. Am J Respir Crit Care Med 2020; 202: 292-296.

45 Tordesillas L, Berin MC, Sampson HA. Immunology of food allergy. Immunity 2017; 47: 32-50.

46 Skypala IJ, McKenzie R. Nutritional issues in food allergy. Clin Rev Allergy Immunol 2019; 57: 166-178.

47 Sdona E, Hallberg J, Andersson N, et al. Dietary antioxidant intake in school age and lung function development up to adolescence. Eur Respir J 2020; 55: 1900990. 